\title{
De Corde-machina: considerações sobre a com-posição da técnica
}

\author{
VÂNIA LÚCIA KAMPFF *
}

\begin{abstract}
RESUMO O presente artigo busca, a partir da conferência "A questão da técnica”, proferida por Martin Heidegger, em 1953, nos acercarmos daquilo que está no fundo da ciência moderna e de entendermos porque ela coloca em questão o homem e o mundo que o cerca.
\end{abstract}

PALAVRAS-CHAVE ciência; técnica; método; real; homem.

Nosso ARTIGo busca, a partir da conferência “A questão da técnica”, proferida por Martin Heidegger, em 1953, entender o modo como, desde a era moderna, a ciência incide o seu pensar sobre o real de modo a trazer algo à luz de uma representação. Trata-se de uma elaboração que corresponde a uma fabricação, na medida em que se firma sobre uma concepção prévia, baseada em métodos, cálculos e delimitação de domínios distintos, que tem por consequência o fato de que a coisa, aquilo que aparece, não é mais aquilo que vem à luz por si mesmo. O horizonte da ciência moderna em nada se aproxima da aurora grega que simplesmente permitia o ser das coisas desabrocharem por si mesmos. Decisivo nisto, não é apenas o fato que o real fica comprometido, mas que toda esta questão será o gatilho para o advento da técnica que, mais do que ser definida como uma mera aplicação da ciência, é, ao contrário, a sua realização máxima. É a técnica a consumação e a plenificação do projeto científico, na medida em que faz do homem parte integrante neste sistema. No âmbito da ciência e da investigação técnica, ambos, o real e o homem, são apenas partes integrantes de uma mesma engrenagem em que o primeiro aparece a partir de uma elaboração prévia de fundos disponíveis de material e o segundo nada mais é do que um zelador desses

* Doutoranda em Filosofia pela PUC-Rio e bolsista CNPq 
fundos. A técnica, mais do que controle e senhorio das máquinas e instrumentos, determina de modo fundamental não só a relação do homem com o mundo, mas, sobretudo, do homem consigo mesmo. Busquemos a origem desta questão.

Foi na Grécia que se constituiu o nexo entre a épistème e a téchnē. Na origem grega, a ciência e a técnica se relacionavam tão naturalmente que muitas vezes entendia-se uma pela outra: a ciência, como uma forma de entendimento com alguma coisa, e a técnica, como identificação do fazer com a própria coisa. Ambas estavam ligadas ao sentido mais amplo do conhecimento. O fato de épistème e téchnē terem esse parentesco não era um problema, pois ambos os saberes buscavam trazer algo à luz em sua essência. Isto significa que há nisso uma relação direta entre o saber e o fazer na sua força geradora. Conhecimento e criação estavam relacionados aos entes em sua totalidade, pois buscavam a coisa na perspectiva de sua essência, colocando-se diante dela de forma que a própria coisa se mostrasse em seu modo de ser. Nem a épistème e nem a téchnē diziam respeito a um modo de compreensão de realidade que tinha por objetivo a finalização de um produto, mas deixavam a coisa vir à presença por si mesma, como uma forma de romper no aberto da sua própria natureza. Lembremos que natureza, em latim, se diz nātūra, que, em sua etimologia, é formada por nāscor e gnāscor que significa nascer, trazer ao mundo. Como forma derivada, temos nātus enātūrus, cujo sufixo -urus, também presente em orìture derivado de orior, significa saltar, brotar, nascer, derivar sua origem; surgir, gerar, a força que gera. ${ }^{1}$ Tudo isso para dizer que aquilo que se mostrava era sempre nascimento, gênese. Assim era a physis grega - pura eclosão e emergir abrupto da coisa desde si mesma, um modo todo próprio de ser e aparecer. Esta é uma afirmação deveras vaga que nos faz interromper o fluxo do pensamento e perguntar: o que é coisa? E mais, como é esse modo todo próprio de ser e aparecer? Algumas palavras se fazem, pois, necessárias.

Coisa já é sempre um mundo, um sentido, um lógos, a partir do qual a coisa aparece como tal. Ver a coisa nela mesma é deixar com que ela apareça desde o mundo que ela é, é sempre ver a partir do seu interesse. Na língua latina, o vocábulo interesse vem de inter-èsse: Inter, dentro; èsse, essere, ser. $^{2}$ Interesse significa, pois, ver sempre

1 ERNOUT; MEILLET, Dictionnaire Etymologique de la Langue Latine: Histoire de Mots, p.429-430 e 468 , respectivamente.

2 ERNOUT; MEILLET, Ibid., p.312 
desde dentro do modo de ser que é o da própria coisa.Mas como é possível ver a coisa desde o seu modo próprio de ser? Não se trata nem de uma visada objetiva e, nem tampouco, subjetiva, mas, de uma abertura a partir da qual a coisa vem a ser a coisa que é. Como dissemos, o que faz uma coisa ser o que ela é é o mundo em que ela está, o mundo em que ela aparece, mas para isso é preciso que o olhar esteja num outro registro, num outro horizonte - o horizonte da transcendência. Não nos deteremos aqui nesta questão, por ora, devemos nos ater apenas ao fato que se trata de uma dimensão - uma possibilidade de vida e existência que sobrevém ao homem, uma vez que ele é tão somente aquele que pode ser tocado e tomado por transcendência. Esta possibilidade de existência está no horizonte do homem, mas ele não tem poder de deliberação sobre isso, ele partilha e participa desta dimensão, mas isto que é a transcendência o ultrapassa. Ele é passagem, aquele que deixa-viger, deixa-ser. Entretanto, não há nisto uma passividade, nem tampouco se trata de uma medida ativa, mas, de estar em sincronia com a própria coisa. A physis como este romper, brotar e eclodir só se dá para um olhar interessado, para um tal olhar que é participe disso e que está na possibilidade do sentido do mostrar-se. Quando se vê assim, há uma abertura - o ver abre um horizonte, uma perspectiva. Isto é o desencobrimento. Para conhecer é preciso estar em sintonia com esta abertura possibilitadora que instaura o aparecer. Se isso acontece, dá-se o conhecer que,no francês - connaître -, tanto quer dizer conhecer como co-nascer ou nascer com. ${ }^{3}$ Esta é uma participação existencial que traz à tona todo um modo de vida. Podemos dizer que, na origem grega, compreendia-se toda e qualquer realidade na medida em que se colocava em estado nascente com a própria coisa. Colocava-se em participação, harmonizava-se e afinava-se à coisa a partir dela mesma. Com isso, a coisa nascia, aflorava, desabrochava em todo o seu esplendor e graça, em pura gratuidade. Este era um sentido elevado de épistème e de téchnē, nisto integra-se a ideia que a natureza não era nada estranho e fora do homem, ela acontecia junto ao seu olhar. O homem não era o autor da natureza, mas, o destinatário que fazia morada em meio aos entes em sua totalidade.

O problema surge quando a ciência emergente da era moderna, cuja força geradora se funda na técnica, em nada se aproxima da épistème da origem que, junto à téchne, via a coisa a partir da própria coisa. A ciência grega nunca foi exata, não havia esta

3 ROBERT, Dictionnaire du Français Primordial, p.212. 
demanda. O próprio télos grego não deve ser entendido como meta ou finalidade, mas, sim, como levar a essência de algo à sua cumulação, plenitude e esplendor. A técnica moderna desconhece completamente isto! Ela é a soma de aptidões que pertencem exclusivamente ao homem e que possibilitam a utilização da natureza para fins humanos. Trata-se simplesmente de um meio para um fim, e uma definição instrumental não pode ser instauração de gênese. O desencobrimento dominante, o modo de realidade se fazendo realidade que rege a técnica moderna é o de exploração e cumulação da ação enquanto operatividade do homem sobre a natureza. Na realidade, trata-se de promover o máximo rendimento possível com um mínimo de esforço. Ortega y Gasset, no livro Meditação da Técnica, entende que um de seus traços mais evidentes é o fato de que ela, na medida em que traz segurança e controle, é um esforço para poupar esforço. Gasset nos fala que a técnica é a reforma da natureza realizada através de atos técnicos que

“[...] não são aqueles em que fazemos esforços para satisfazer diretamente nossas necessidades, sejam estas elementares ou francamente supérfluas, mas aqueles em que dedicamos o esforço, primeiro, para inventar e, depois, para executar um plano de atividades[...].”4

A ideia de mínimo esforço deve ser aprofundada à luz de uma frase de Heidegger que diz: "A ciência é a teoria do real." 5 Incide sobre ela a ideia de que o que vem à luz, o real, é uma teoria elaborada pela ciência moderna que tem por trás o homem. Trata-se, como dissemos no início, de uma elaboração fabricadaque se alicerça sobre uma construção prévia que se assenta em métodos, os quais têm como resultado um real pré-fabricado. Na técnica moderna, a natureza é submetida e subjugada a um processo de absoluto controle dado pela subjetividade operante que a manipula objetivadamente. Assim, mais do que ser apenas um meio para satisfazer as necessidades do homem, promove-se uma verdadeira reforma da natureza realizada através de atos técnicos, os quais visam assegurar a satisfação de resultados. Isto é muito grave! A técnica acaba por ser um sistema que dispõe de informações que descartam por completo a coisa em sua gênese. O que interessa é apenas o seu índice informativo. Teorizar é, pois, estabelecer relações de informação, índices de controle, e pouco

5 HEIDEGGER, "Ciência e pensamento de sentido", in: Ensaios e Conferências, p.40. 
interessa o sentido ontológico, a experiência. Isto é o nivelamento e o achatamento completo da terra! O que interessa, em última instância, é o controle: um mecanismo que funcione como asseguramento sobre alguma coisa. Por consequência, assim também será arealidade: o objeto de uma representação, ou seja, não há uma realidade concreta, mas, apenas teorias que a constrói. Isto em nada tem a ver com ideia de teoria elaborada na Grécia que, de alguma forma, possuía uma significação mais nobre. Na origem, o substantivo theōría provinha do verbo grego theōreinque, por sua vez, nasceu de dois outros termos: théa, que quer dizer fisionomia, o perfil de algo e como ele se mostra - como em théatron, o lugar em que se vê e em theáomai, a visão que se oferece. Platão criou o termo eîdos para falar desse perfil em que o vigente mostra o que ele é; o outro termo derivativo é horáō, que significa ver e tomar algo sob os olhos; na forma figurada, ver com a mente, compreender. ${ }^{6}$ Isto significa que, na aurora grega, teoria era "visualizar a fisionomia em que aparece o vigente, vê-lo e por esta visão ficar sendo com ele”. ${ }^{7}$ Isto é conhecer, é co-nascer, a visão em sua forma mais requintada e o pensamento em sua forma mais elevada.

No modo de ser que é o da tecnologia virá à tona uma com-posição, a saber, o arranjo de toda a realidade compreendida objetivadamente como fonte de energia, com a simples finalidade de estocá-la como um depósito sempre disponível para uso.Heidegger chega a cunhar uma palavra para esta com-posição: Ge-stell. Há nesta palavra toda uma estrutura, uma fabricação, uma esquematização para ajustar tudo de modo a virar recurso, insumo, matéria-prima. E não só isto! A com-posição é a força de reunião daquilo que está postoe que compele o homem a desencobrir o real como dis-ponibilidade. Isto nada mais é do que um chamado explorador que tem como essência o desencobrir do real de forma a que este seja apenas um fundo de reserva.Este é o modo como se vê toda a realidade. Hoje, quando se vê um rio, não se vê o rio, se vê aquilo que o rio tem como propriedade para a fabricação de bens, o que nele tem de mão de obra, de lucro, e, nesse emaranhado de fios, o que está sempre enredada é a estrutura da com-posição. Vê-se tudo isso, menos o rio. Spengler, no livro O Homem e a Técnica, faz uma crítica bastante ácida ao homem. Para ele, o homo technicus possui uma

6 LIDDELL; SCOTT, A Greek-English Lexicon, p. 796-797, 1244, respectivamente.

7 HEIDEGGER, “Ciência e pensamento de sentido”, in: Ensaios e Conferências, p.45. 
alma que avança cada vez mais, num sempre crescente alheamento da natureza. [...] O Homem arrebatou à Natureza o privilégio da criação [...] se libertou dos laços da Natureza e com cada criação nova se afasta cada vez mais dela, torna-se cada vez mais seu inimigo. ${ }^{8}$

Isto significa que a natureza é descartada e encarada apenas como um eficaz sistema operacional de forças previamente manipulado de modo a confirmar a condição pré-estabelecida pela teoria,como num arquivo de regras e normatização; uma fórmulatotalmente artificial do projeto antecipatório científico. Isso é o lógos moderno, o sentido contemporâneo, o modo como tudo aparece previamente, por antecipação. O que impera é o espírito calculador, o qual não deixa espaço para a liberdade, para o desabrochar da coisa por si mesma e, nem sequer, para o inesperado, para a possibilidade de algo chegar até o homem. Lembremos de Heráclito que, no fragmento 18, diz: "Se não se espera não se encontra o inesperado, sendo sem caminho de encontro nem vias de acesso.”9 Há que se esperar o inesperado! A técnica moderna simplesmente apodera-se da téchnē como um modo de produção, dela se apropria e insaciavelmente a conduz ao inatingível, ao inalcançável, ao infinito. Este é um envio que é um desvio. Logo nos vem a pergunta: por que o destinar da técnica é um desvio? Recuperemos para avançar.

Dissemos que, na origem grega, a téchnē era um movimento de promoção de gênese e geração da physis. O fazer do homem estava de tal maneira sintonizado com este movimento, que ele participava desta produção, mas ele não se entendia como o autor. Em contrapartida, o homem da técnica já aparece como o criador, um eu constituído que, por sua vez, é constituinte, produtor, organizador, anunciador e programador do real. A natureza acaba por ser apenas uma posição e objetivação desse sujeito. Trata-se, como vimos, de uma realidade regida por uma exploração que impõe à natureza um modo de ser que nada tem a ver com a physis grega. Na modernidade, a natureza é apenas um grande armazém e a técnica é o modo como a ciência moderna se evidência no seu projeto. Não nos reportamos aqui à uma experiência, mas, sim, a um experimento. O experimento é a antecipação e a programação da experiência.Elabora-se uma teoria, que nada mais é do que uma hipótese, uma pressuposição que será tes-

8 SPENGLER, O Homem e a Técnica, p.68-69.

9 HERÁCLITO, "Fragmentos", in: Os Pensadores Originários: Anaximandro, Parmênides, Heráclito, p.63. 
tada até o ponto em que se tenha o controle sobre aquele fenômeno. Enquanto isto não acontece, volta-se ao experimento. Quando se consegue o resultado esperado, o experimento torna-se verdadeiro e real. Nesta história toda, o que menos interessa éo conhecer ou o saber na compreensão que havíamos falado, que é o de ver ou participar de uma coisa no seu sentido ontológico, no seu sentido de ser. Isso não interessa! O que interessa é o querer científico e a necessidade de controle e esquematização. Kant, na introdução à Crítica da Razão Pura, referindo-se à forma como Galileu e Torricelli interrogam a natureza, diz que eles

compreenderam que a razão só entende aquilo que produz segundo os seus próprios planos; que ela tem que tomar a dianteira com princípios que determinam os seus juízos, segundo leis constantes, e deve forçar a natureza a responder às suas interrogações, em vez de se deixar guiar por esta. ${ }^{10}$

Isto significa que o que passa a valer não é a verdade, mas a função de controle que ela ocupa. A verdade passa a ser subentendida como parâmetro e grau de certeza e segurança. Trata-se, como acabamos de ver, de uma antecipação planejada do experimento que precisa se ajustar e adequar ao esquema proposto pela ciência.Isto é uma exploração desafiadora, pois é o homem da técnica que - movido por mecanismos de extração, transformação, estoque, distribuição, reprocessamento, e sabe-se lá mais o quê! - conduz a pergunta ao seu bel prazer. Decisivo nisso é que é o homem que promove esta exploração. Ruminando por trás, está a vontade humanaregida pela autonomia do euque retroalimenta e intensifica o movimento de certeza do controle e, com isso, ocorre uma modificação na própria essência do homem, queperde o limite e se move ao infinito - quer controlar o controle e assegurar o asseguramento.

A cumulação de uma essência é a plenificação de algo. No caso da técnica, é a plenificação da hýbris, do excesso, do descomedimento. A terra passa a ser um grande almoxarifado e o homem o dono dessa chave. Lembremos que, no mito, Ícaro é a personificação da hýbris, é o símbolo da volúpia e da megalomania. Mesmo admoestado pelo pai que lhe pedia para que guardasse a medida entre as ondas do mar e os raios de sol, ele ultrapassa o metrón, amedida do possível, e, voando além,destrói-se. A hýbris é, pois, a ultrapassagem da medida, é a desmesura através da qual o homem se esquece que é um simples mortal. Lembremos também que, no mito de Hesíodo, a medidado 
homem é dada pelo "ser". O homem é dimensionado pelo trabalho e pela justeza de suas medidas. Em Hesíodo, o ánthropos,é homo, húmus, o barro, a argila, aquele que descende de Epimeteu e Pandora, que precisa ganhar a vida com o suor do seu rosto e que, por isto, está completamente integrado ao ser da sua medida. ${ }^{11}$ Esta pequena digressão ao mundo do mito nos faz entender o desvio que a técnica impõe ao homem, o quanto ela o afasta do seu modo próprio de ser. Como mestre e senhor da natureza, o homem da técnica é o onipotente, aquele que tudo sabe e tudo pode - o próprio deus. Trata-se da exacerbação máxima da autonomia da subjetividade, do sujeito que quer organizar e planificar tudo de acordo com esse querer que tudo quer. O problema é o homem se colocar como destino de tornar-se aquilo que ele não pode ser - o senhor da terra e da realidade. Isto é volúpia! É um excesso que se põe como um valor supremo, mas que também se mostra como uma impossibilidade, pois querer o impossível não pode ser a meta do homem. A essência da técnica é uma armação que, de modo dissimulado e perverso, deixa o homem à serviço e à mercê desta com-posição. $\mathrm{O}$ niilismo aparece como a reverberação deste fundo vital existencial que envolve, se apropria e se apodera do homem, lugar em que impera a sanha, a vontade do infinito e do ilimitado. Isto significa que a técnica não somente envolve a mutação da natureza, mas, sobretudo, da essência do próprio homem. O domínio total da realidade armado pela estrutura da disponibilidadecompromete a própria existência humana. A técnica moderna, velada e silenciosamente, encaminha o homem para um grande deserto, para a derrocada completa do poder do espírito e, como bradava Nietzsche, em Assim falou Zaratustra: “ai daquele que abriga desertos!”. ${ }^{12}$ Há uma tendência do mundo moderno se uniformizare unidimensionalizar, tamanha é a força de achatamento e nivelamento da realidade, que não deixa nenhuma outra possibilidade de ser. Este é o nível mais superficial da existência humana. Isto é o grande perigo! Isto é o deserto! Isto é o desvio!

11 BRANDÃO, Mitologia Grega, v.1, p.165.

12 NIETZSCHE, Assim falou Zaratustra, p.294. 


\section{REFERÊNCIAS BIBLIOGRÁFICAS:}

BRANDÃO, J. Mitologia Grega. Volume I. Petrópolis: Vozes, 1986.

ERNOUT, A.; MEILLET, A. Dictionnaire Etymologique de la Langue Latine. Paris: Klincksieck, 2001.

FOGEL, G. Da Solidão Perfeita - Escritos de Filosofia. Petrópolis, RJ: Vozes, 1998.

HEIDEGGER, M. Caminhos de Floresta. Trad. Irene Borges Duarte et al. Lisboa: Fundação Calouste Gulbenkian, 2012a.

. Ensaios e Conferências. Trad. Emmanuel Carneiro Leão, Gilvan Fogel e Márcia Sá Cavalcante Schuback. Petrópolis:Vozes; Bragança Paulista: Editora Universitária São Francisco, 2012b.

. Heráclito. Trad. Márcia Sá Cavalcante Schuback. Rio de Janeiro: Relume Dumará, 1998.

HERÁCLITO. Fragmentos -Os Pensadores Originários: Anaximandro, Parmênides, Heráclito. Trad. Emmanuel Carneiro Leão. Petrópolis: Vozes, 1991.

KANT, E. Crítica da Razão Pura. Trad. Manuela Pinto Dos Santos e Alexandre Fradique Morujão. Lisboa: Fundação Calouste Gulbenkian, 2001.

LIDDELL, H.G.; SCOTT, R. A Greek-English Lexicon. New York: Oxford University Press Inc., 1996.

NIETZSCHE, F. Assim Falou Zaratustra. Trad. Paulo César de Souza. São Paulo: Companhia das Letras, 2011.

ORTEGA Y GASSET, J. Meditação da Técnica - Vicissitudes das Ciências. Cacofonia na Física.Rio de Janeiro: Livro Ibero-Americano Limitada, 1963.

ROBERT, P. Micro Robert - Dictionnaire du Français Primordial. Paris: Brodard et Taupin, 1981.

SPENGLER, O. O Homem e a Técnica - Contribuição à uma filosofia de vida. Trad. Érico Veríssimo. Porto Alegre: Edições Meridiano, 1941. 